\title{
Promoting Alternative Teaching-Professor Hires: A New PATH for Engineer- ing State University
}

\section{Dr. Cheryl Cass, North Carolina State University}

Cheryl Cass is a teaching assistant professor in the Department of Materials Science and Engineering at North Carolina State University where she has served as the Director of Undergraduate Programs since 2011.

\section{Dr. Lisa G. Bullard P.E., North Carolina State University}

Dr. Lisa Bullard is an Alumni Distinguished Undergraduate Professor and Director of Undergraduate Studies in the Department of Chemical and Biomolecular Engineering at North Carolina State University. She received her BS in Chemical Engineering from NC State and her Ph.D. in Chemical Engineering from Carnegie Mellon University. She served in engineering and management positions within Eastman Chemical Company from 1991-2000. A faculty member at NC State since 2000, Dr. Bullard has won numerous awards for both teaching and advising, including the ASEE Raymond W. Fahien Award, the John Wiley Premier Award for Engineering Education Courseware, NC State Faculty Advising Award, National Effective Teaching Institute Fellow, NC State Alumni Outstanding Teacher Award, George H. Blessis Outstanding Undergraduate Advisor Award, and the ASEE Southeastern Section Mid-Career Teacher Award. She is a member of the editorial board for Chemical Engineering Education and serves a Director of the Chemical Engineering Division of ASEE. She will be a co-author, along with Dr. Richard Felder and Dr. Ronald Rousseau, of the 4th edition of Chemical Process Principles. Dr. Bullard's research interests lie in the area of educational scholarship, including teaching and advising effectiveness, academic integrity, process design instruction, and the integration of writing, speaking, and computing within the curriculum.

\section{Dr. Anita R. Vila-Parrish, North Carolina State University}

Dr. Anita Vila-Parrish is the Director of Undergraduate Programs and Teaching Assistant Professor in the Edward P. Fitts Department of Industrial \& Systems Engineering. Currently, Dr. Vila-Parrish is teaching and coordinating the senior design project course as well as advising the ISE undergraduates. Related to her teaching and advising she is interested in research focused on engineering education topics including project-based learning in engineering design and global preparedness. Dr. Vila-Parrish continues research in inventory and production strategies for perishable products and those with short product lifecycles. 


\title{
Promoting Alternative Teaching-Professor Hires: A New PATH for NC State University
}

\begin{abstract}
According to recent literature, non-tenure-eligible or non-tenure-track (NTT) faculty comprise between 50-75\% of current 2-year and 4-year university faculty members and new university faculty hires. Women comprise a disproportionate number of full-time NTT faculty and there are limited studies that assess the work environment of this faculty group. The purpose of this work is to discuss recent survey data collected from NTT faculty at NC State University (NCSU) to describe current efforts by NTT faculty in engineering to promote development and collaboration between NTT faculty, and to make recommendations for improving the university culture for hiring, fostering, and promoting NTT faculty. The Collaborative on Academic Careers in Higher Education (COACHE) survey is a nationally-recognized instrument that is administered to all university faculty at NCSU on a triennial basis with the purpose of assessing faculty satisfaction in various domains of university life including available resources, promotion policies, benefits and compensation, department collegiality, quality, and engagement, and interdisciplinary work and collaboration. For this work, we will focus on recent interventions that have resulted from the COACHE data, specifically discussing improvements in the promotion process for NTT faculty and the development of a NTT support group in NCSU's College of Engineering.
\end{abstract}

The Office of Faculty Development in NCSU's College of Engineering initially spearheaded a discussion of best practices for NTT faculty career development and promotion in Fall 2011. Promotional policies that have already been adopted at the University level will be discussed, including those related to letters of support, expectations for national and international visibility, and department voting. Future work at NCSU will focus on NTT faculty career enrichment in addition to the development of more standard procedures for recognizing and evaluating the external impact of research, teaching, and outreach efforts of NTT faculty.

\section{Experiences of Women Faculty in STEM}

There has been a renewed focus on exploring gender differences in academia. While increases in female graduate students have occurred at the doctorate level, this has not translated to a proportional difference in female STEM faculty, and the resulting statistics show a continued disproportionately lower number of women entering the academe. Xu (2008) explores this issue by studying the turnover and attrition issues faced by women faculty. ${ }^{6}$ Studies have approached these concerns by exploring the mechanisms that drive these issues. Barbezat (1992) has attributed some of these issues to work environments that are not seen a collaborative or teaching-focused. Further, Barbezat argues that women perceive these environments, especially in STEM fields, to be isolating. ${ }^{2} \mathrm{Xu}$ (2008) goes on to summarize many studies that point to the social and political biases that limit opportunities for women. For example, the author states that "In reality, such structural-related gender biases mean that women have a smaller chance of being hired; the small group of women who start faculty careers in STEM suffer isolation, marginalization, stereotyping, insufficient support, delay in advancement, and other adversity at work."6 
According to recent literature, non-tenure-eligible NTT faculty comprise between $50-75 \%$ of current 2-year and 4-year university faculty members and new university faculty hires. With the growth in NTT faculty, it is interesting to note that research exploring the experiences of women in NTT roles is quite limited. Recent estimates show a disproportionate number of women in NTT roles in the academe. West and Curtis (2006, p 9) state that "women are significantly overrepresented in these non-tenure track positions, [which are] the least secure, least remunerative, and least prestigious jobs among the full-time faculty" making up 52\% of full time faculty in this group. ${ }^{5}$ Hart (2011) calls for a need to understand the climate for women in these roles in order to create an environment that cultivates success and respect. ${ }^{4}$ Chronister and Baldwin (1999) and Baldwin and Chronister (2001) studied the work life of full-time NTT faculty (men and women) at four-year institutions through the use of surveys, secondary data (National Survey of Postsecondary Faculty), and faculty interviews. ${ }^{1-2}$ Hart (2011) summarized their results as "nontenure track faculty experienced boredom in teaching the same classes each semester, raised concerns about not being able to participate in faculty governance, and were frustrated at the lack of support for conducting research". She expanded upon this work and found that while nontenure track women were primarily satisfied in their work, they were not always treated equitably. She calls for the following three areas of future focus: (1) "faculty and institutions must establish and monitor clear guidelines about the roles and expectations of non-tenure track faculty" (2) "departments, colleges, and universities must provide opportunities for faculty development and related resources, including internal research support, conference travel money, involvement in colloquia, and access to teaching and grant writing workshops" (3) "faculty mentoring programs are crucial". 4

At NCSU there has been an increased focus in the College of Engineering (COE) to address the concerns identified by the studies discussed above. In the following section we will discuss the formation of a support group for faculty in the COE who hold teaching faculty ranks.

\section{Activities and Formation of NTT Support Group in Engineering}

NCSU initiated a Teaching Professor track in 2005. Prior to that time, faculty who had primarily teaching responsibilities were classified as Lecturers. While there are still faculty whose classification remain Lecturer based with regard to their job responsibilities, most of the teaching-focused new hires in NCSU's College of Engineering since 2005 have entered the Teaching Professor track. Some individuals who were already classified as Lecturers were migrated to Teaching Assistant, Associate, or Full Professors, depending on their experience and qualifications. There are currently $36 \mathrm{COE}$ faculty in the Teaching Professor track spanning all twelve engineering disciplines and three administrative units, with 23 Teaching Assistant Professors, 12 Teaching Associate Professors, and 3 Teaching Professors. Of the current group on a teaching professor track, $46 \%$ are female, compared to $18 \%$ female in the tenure track faculty within the College of Engineering. In 2010, the NCSU Provost released the latest white paper detailing best practice recommendations for the administration of NTT policies related to standardized position titles, professional development, support, recognition, evaluation, promotion, contracts, faculty governance and salary. Following this initiative, in 2011 a group of three Teaching Professors initiated a NTT Learning Community within COE, whose objective was to build a learning and support system for COE Teaching Professors at all levels. The initial goals of the group were as follows: 
- Facilitate networking so that faculty can identify potential collaborators as well as mentors

- Share information related to promotion and tenure for the Teaching Professor track

- Increase awareness of the Teaching Professor role within the college

It is worth noting that while $46 \%$ of the Teaching Professor ranks in the College of Engineering are female, average attendance at the community's events has ranged from $63 \%$ to $80 \%$ female, indicating that the female non-tenure track faculty have a strong interest in networking, learning more about promotion and tenure, and improving their teaching. Female faculty have also taken a leadership role in this group, with the current leaders being $100 \%$ female. Female faculty in this group have gotten involved with the NTT organization on campus and have taken a leading role in drawing attention to the concerns of NTT faculty.

\section{Results of Initial Interest Survey}

Based on interest expressed at the group's initial meeting, a survey was conducted to determine the group's top priorities and interests. The survey results from the initial group of NTT faculty are shown below in Figures 1-3:

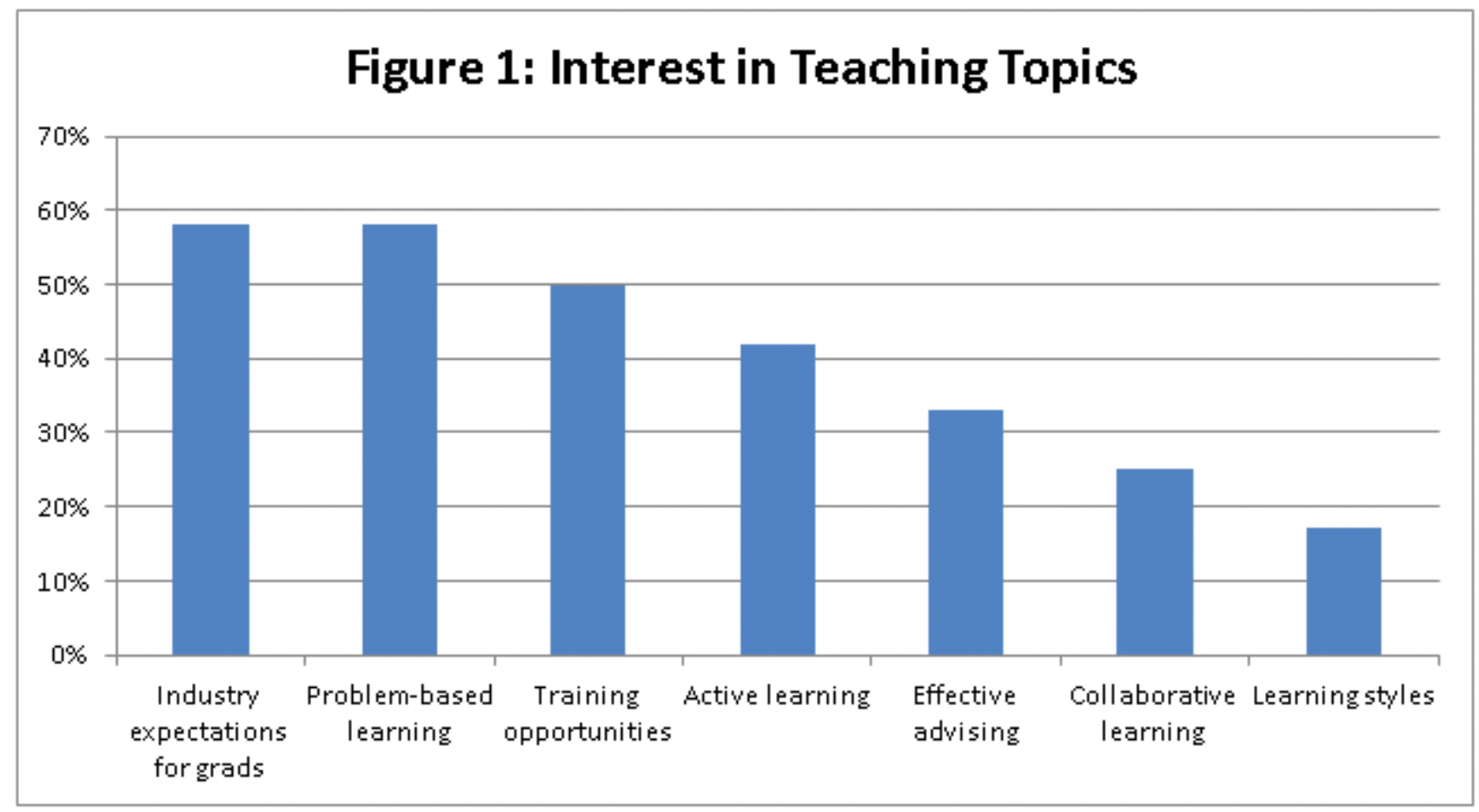




\section{Figure 2: Interest in Educational Research Topics}
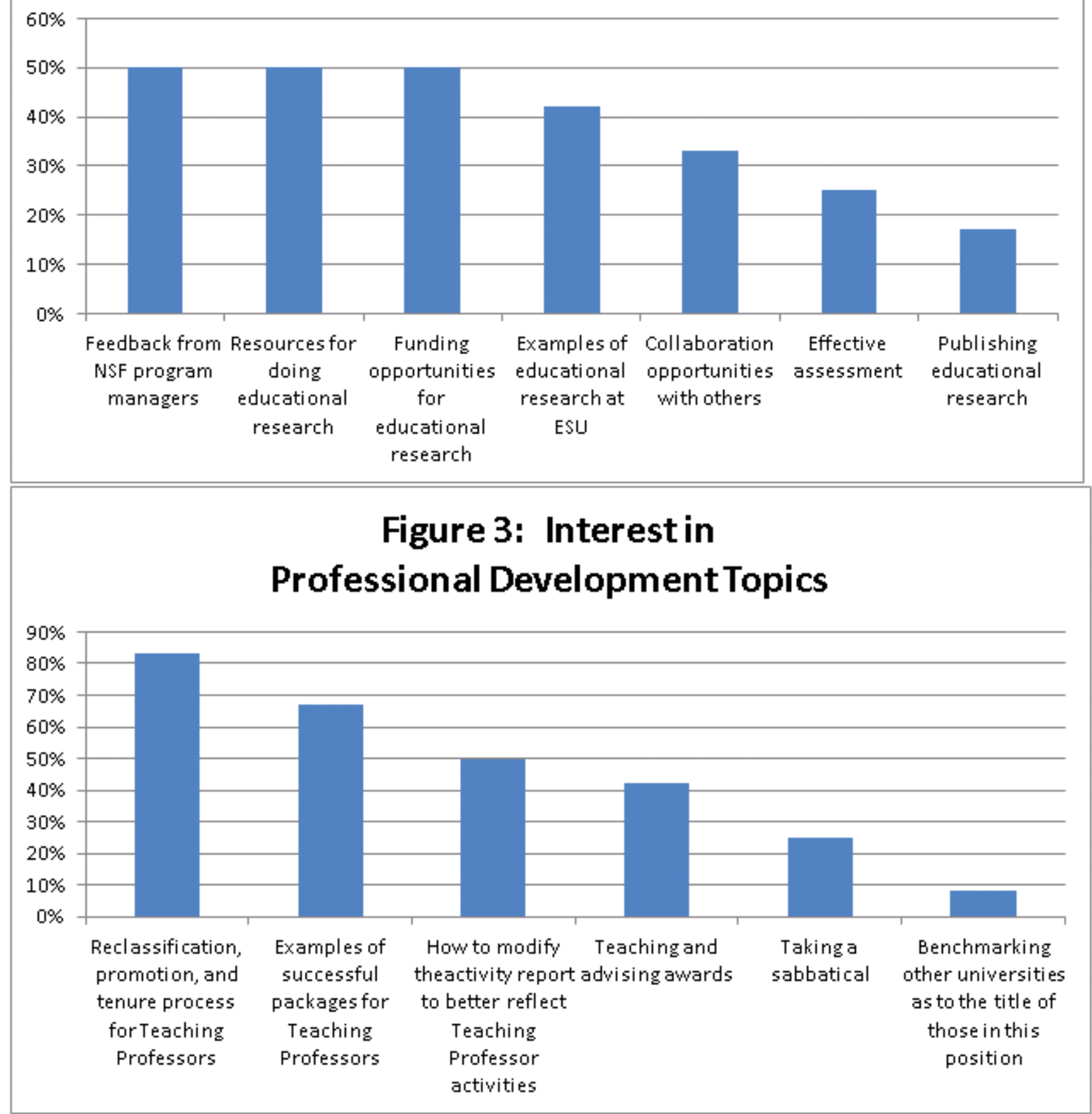

To support the NTT Learning Community survey, the authors (in collaboration with NCSU's Office of University Planning and analysis) evaluated the results of the NCSU COACHE survey in order to more clearly define our group's challenges and goals and to develop an awareness of how NTT issues in the College of Engineering span the University. The Collaborative on Academic Careers in Higher Education (COACHE) survey is a nationally-recognized instrument that is administered to all university faculty at NCSU on a triennial basis with the purpose of 
assessing faculty satisfaction in various domains of university life including available resources, promotion policies, benefits and compensation, department collegiality, quality, and engagement, and interdisciplinary work and collaboration. Because of the small sample size of NTT faculty in the College of Engineering on a teaching track and the potential for compromising anonymity, all data is based on the core university group of NTT faculty. There are no NCSU peer comparisons for the NTT portion of the survey. According to the 2011-2012 NCSU COACHE summary report, NTT faculty had a $46 \%$ response rate. or 197 out of 432 . NTT respondents indicated the following appointment types: "lecturer" (41\%), "teaching" (29\%), "research" (11\%), "clinical" (7\%), "extension" (7\%) and "other" (5\%). The gender breakdown for NTT respondents was $52 \%$ female and $48 \%$ male. When asked about primary work responsibilities, nearly $60 \%$ of NTT faculty at NCSU indicated that teaching was a primary responsibility. Approximately $21 \%$ of NTT faculty indicated being responsible for an equal amount of 2 or more activities including teaching, research, administration, and outreach. Most (92\%) of NCSU's NTT faculty are on fixed-term renewable contracts; other contract types included "rolling" (4.7\%), "other" (3.1\%), and "fixed-term nonrenewable" (0.5\%). Some NTT faculty $(28 \%)$ held additional administrative titles such as "Center/Program Director,"

"Associate/Assistant Head/Chair," etc.

When asked about overall satisfaction working at NC State University, $72 \%$ are satisfied with NCSU as a place to work [compared to $60 \%$ for T/TT], and $70 \%$ intend to stay at NCSU for 10 or more years [compared to $48 \%$ for T/TT]. Overall, the top areas of dissatisfaction by NTT faculty are: compensation (49\%), teaching load (12\%), lack of support for professional development (10\%), lack of support for teaching (9\%), quality of facilities (9\%), or no negative aspects (9\%). When asked what would compel them to leave NCSU, 25\% indicated an improvement in salary and benefits, while $12 \%$ would seek improvement in the prospects for promotion. Among the most favorably rated aspects of work for NTT faculty at NCSU were discretion over a course's content, time spent on teaching, library resources, and opportunities for being a mentor. Among the least favorably rated aspects of work for NTT faculty at NCSU were promotion processes, standards and criteria, lack of course release for research, compensation/benefits, mentoring/support, interdisciplinary work, and department life. Interestingly, NTT faculty were more likely than tenured/tenure-track faculty to give favorable responses, particularly for questions related to support for research and teaching, personal and family policies, health and retirement benefits, and leadership and governance. However, when compared with tenured/tenure-track faculty, NTT faculty at NCSU were less likely to give favorable responses to questions regarding department life, appreciation and recognition, influence over research focus, and external mentoring, and collaboration. Based on COACHE results, NCSU's administration has identified the top 3 areas of concern for NTT faculty that need to be addressed: 1 . promotion related procedures and expectation, 2. salary and benefits, and 3. department fit and interactions.

\section{Discussion and Outcomes from Initial Meetings}

To follow up on some of these major areas of concern that were identified both in the COE and at the University level, one of the first NTT Learning Community meetings was spent reviewing the RPT (Reappointment, Promotion, and Tenure) process with the Vice Provost for Faculty 
Affairs and the Director of the Office of Faculty Development in COE, who also chairs the RPT Committee for the College. Issues of concern included the following:

- What kind of training do Departmental Voting Faculty receive for NTT promotion evaluations?

- How are NTT faculty are evaluated against the standards of their department and within the context of College and Department RPT rules?

- How is "scholarly activity" defined? It is more than what happens in the classroom? This could include service responsibilities, participation/leadership in professional organizations outside the university, attending workshops, sitting on panels, etc. In other words, "talking and thinking about teaching".

- For someone whose expectations center on teaching alone, a lecturer position may be more appropriate than a Teaching Professor track position since it may be difficult to demonstrate external impact/get external letters.

- Evaluation consists of (a) Statement of Mutual Expectations (SME) (your agreed upon assignment), (b) departmental rules (the level of quality expected) and (c) your annual review/assessment (are you meeting these expectations).

- Do successful candidates have to have something to "show" in every realm of responsibility? No. But you do need to show that you are doing the items on the SME really well. Other things can be added (administrative assignments, service, etc.) You may have something in the dossier that is not on the SME - you can still include it.

- At NCSU, there is no "clock" for promotion for Teaching Professor track faculty. It is not "up or out". You can stay at a given level if you choose and continue in the same rank.

As a result of this meeting, the following are recommendations for NTT faculty in the College of Engineering based on newly adopted administrative guidelines:

- Know the policies and regulations that affect your employment. These are available on the university's web site.

- Review your Statement of Mutual Expectations (SME) with your Department Head and discuss how these may need to change if you plan to pursue promotion.

- Make sure that you are getting a formal Peer Evaluation of your teaching on a routine basis, as designated by your department. This is a critical component in the review and promotion processes.

- Discuss the issue of promotion with your Department Head at your annual review.

- Be sure your Department Head knows of your interest to submit your dossier for promotion by the previous Spring. Departments submit a list of those "going up" in the early fall, when packages are due.

- Consider requesting a milestone review by the Departmental Voting Faculty in advance of going up for promotion. This helps the faculty see what you are doing and provides a chance for early feedback.

- Take advantage of opportunities to hone your teaching skills, demonstrate leadership and contribution on- and off-campus, and obtain recognition for your work:

- Pursue on- and off-campus teaching workshops, such as the National Effective Teaching Institute. ASEE also offers regional and national workshops as well as opportunities for 
leadership in specific divisions of interest, and there are on-campus programs through the NCSU Office of Faculty Development.

- Participate in course and curriculum committees and other service activities.

- Pursue teaching and advising awards.

- We have an opportunity to guide the process for the promotion of NTT faculty. There is not much detail in COE regulations about the NTT expectations. Working with the COE Faculty Development Unit, we can provide feedback and suggestions to the College on issues that need to be addressed for NTT faculty.

\section{Conclusions}

One of the main objectives of the group was to share information and resources and help NTT faculty make connections with each other. To accomplish this objective, the following are examples of information that the group has shared through their website and listserv:

- Profiles of teaching faculty (links to web pages)

- Research and/or teaching interests

- Resources for educational research

- Training opportunities in teaching

- Funding opportunities in engineering education

- Information about teaching and advising awards

- Successful promotion packages

As a result of discussions within the COE group, individuals from the group were invited to serve on the University's NTT Task Force to have input into university policies regarding NTT faculty. In addition, feedback from the group influenced the decision by the College of Engineering to not require external letters for promotion from Teaching Assistant Professor to Teaching Associate Professor, and to require external letters for promotion from Teaching Associate Professor to Teaching Professor. One example of an activity which came out of this group was a visit to the NSF Education Directorate in May 2013 in which 7 faculty took a day trip to meet with NSF Program Managers to discuss educational research opportunities.

While this COE NTT group is still in its infancy it has made significant strides in addressing some of the initial concerns raised by its members and the literature. Of future interest is studying how these concerns are perceived by the men versus women who make up this group.

\section{References}

1. Baldwin, R.G., \& Chronister, J.L. (2001). Teaching without tenure. Baltimore, MD: Johns Hopkins University Press.

2. Barbezat, D. A. (1992). The market for new Ph. D. economists. Journal of Economic Education, Summer, 262275.

3. Chronister, J.L., \& Baldwin, R.G. (1999). Marginal or mainstream? Full-time faculty off the tenure track. Liberal Education, 85(4), 16-23. 
4. Hart, J. (2011). Non-tenure track women faculty. Journal of the Professoriate, 4(1), 96-124.

5. West, M.S., \& Curtis, J.W. (2006). AAUP faculty gender equity indicators 2006. Washington, DC: American Association of University Professors.

6. Xu, Y.J. (2008). Gender Disparity in STEM Disciplines: A Study of Faculty Attrition and Turnover Intentions. Res High Educ,49:607-624 